\title{
Neuroprotective effect of a novel Chinese herbal decoction on cultured neurons and cerebral ischemic rats
}

Fanny Chui-Fun I $\mathrm{p}^{1,2,3^{\dagger}}$, Yu-Ming Zhao ${ }^{1,5+}{ }^{1}$ Kim-Wan Chan ${ }^{1,2}$, Elaine Yee-Ling Cheng ${ }^{1,2}$, Estella Pui-Sze Tong ${ }^{1,2}$, Oormila Chandrashekar', Guang-Miao Fu ${ }^{1,2}$, Zhong-Zhen Zhao ${ }^{4}$ and Nancy Yuk-Yu Ip $p^{1,2,3^{*}}$

\begin{abstract}
Background: Historically, traditional Chinese medicine has been widely used to treat stroke. Based on the theory of Chinese medicine and the modern pharmacological knowledge of herbal medicines, we have designed a neuroprotective formula called Post-Stroke Rehabilitation (PSR), comprising seven herbs - Astragalus membranaceus (Fisch.) Bunge, Salvia miltiorrhiza Bunge, Paeonia lactiflora Pall., Cassia obtusifolia L., Ligusticum chuanxiong Hort., Angelica sinensis (Oliv.) Diels, and Glycyrrhiza uralensis Fisch. We aim to examine the neuroprotective activity of PSR in vitro and in vivo, and to explore the underlying molecular mechanisms, to better understand its therapeutic effect and to further optimize its efficacy.

Methods: PSR extract or vehicle was applied to primary rat neurons to examine their survival effects against $\mathrm{N}$ methyl-D-aspartate (NMDA)-elicited excitotoxicity. Whole-cell patch-clamp recording was conducted to examine the NMDA-induced current in the presence of PSR. ERK- and CREB-activation were revealed by western blot analysis. Furthermore, PSR was tested for CRE promoter activation in neurons transfected with a luciferase reporter. The protective effect of PSR was then studied in the rat middle cerebral artery occlusion (MCAO) model. MCAO rats were either treated with PSR extract or vehicle, and their neurobehavioral deficit and cerebral infarct were evaluated. Statistical differences were analyzed by ANOVA or t-test.
\end{abstract}

Results: PSR prominently reduced the death of cultured neurons caused by NMDA excitotoxicity in a dosedependent manner, indicating its neuroprotective property. Furthermore, PSR significantly reduced NMDA-evoked current reversibly and activated phosphorylation of ERK and CREB with distinct time courses, with the latter's kinetics slower. PSR also triggered CRE-promoter activity as revealed by the increased expression of luciferase reporter in transfected neurons. PSR effectively reduced cerebral infarct and deficit in neurological behavior in MCAO rats when PSR decoction was administered starting either 6 days before or $6 \mathrm{~h}$ after onset of ischemia.

Conclusions: PSR is neuroprotective both in vitro and in vivo - it protects cultured neurons against NMDA excitotoxicity, and effectively reduces ischemic injury and neurobehavioral deficit in MCAO rats in both the pre- and post-treatment regimens. The underlying neuroprotective mechanisms may involve inhibition of NMDA receptor current and activation of ERK and CREB. This study provides important preclinical data necessary for the further development of PSR for stroke treatment.

Keywords: TCM, Stroke, MCAO, Neuroprotection, Excitotoxicity, NMDA receptor, ERK, CREB

\footnotetext{
* Correspondence: boip@ust.hk

${ }^{\dagger}$ Equal contributors

${ }^{1}$ Division of Life Science, The Hong Kong University of Science and

Technology, Clear Water Bay, Hong Kong, China

${ }^{2}$ State Key Laboratory of Molecular Neuroscience, The Hong Kong University

of Science and Technology, Clear Water Bay, Hong Kong, China

Full list of author information is available at the end of the article
}

(c) The Author(s). 2016 Open Access This article is distributed under the terms of the Creative Commons Attribution 4.0 International License (http://creativecommons.org/licenses/by/4.0/), which permits unrestricted use, distribution, and reproduction in any medium, provided you give appropriate credit to the original author(s) and the source, provide a link to the Creative Commons license, and indicate if changes were made. The Creative Commons Public Domain Dedication waiver (http://creativecommons.org/publicdomain/zero/1.0/) applies to the data made available in this article, unless otherwise stated. 


\section{Background}

Stroke, which can be hemorrhagic or ischemic, is caused by the bursting or blockade of blood vessels, respectively. It is one of the leading causes of death and disability worldwide, and $85 \%$ of all stroke cases are ischemic [1-3]. Recombinant tissue plasminogen activator (rtPA), an enzyme that breaks down blood clot aiming to restore blood reperfusion, is the only FDA-approved pharmacological treatment for ischemic stroke [1-3]. However, its application is restricted because of a narrow administration time window of $\sim 3$ to $4.5 \mathrm{~h}$ after the initiation of ischemia [4]. Hence, there is an urgent need for novel stroke treatments, and different neuroprotective strategies that counteract the molecular cascades responsible for ischemic injury have been proposed [3, 5-8]. Mechanisms that contribute to ischemic injury include glutamate excitotoxicity, oxidative damage, inflammation and apoptosis; molecular targets for neuroprotection include calcium channel, glutamate receptor, $\mathrm{GABA}_{\mathrm{A}}$ receptor, PSD95, nitric oxide synthase and extracellular adhesion molecule [3, 5-8]. In particular, one neuroprotective strategy targets the $\mathrm{N}$ methyl-D-aspartate receptor (NMDAR) which plays a critical role in mediating glutamate excitotoxicity and neuronal death [9-11]. Interestingly, NMDAR also mediates pro-survival signaling that is beneficial to neuronal survival upon cerebral ischemic attack, via Akt and ERK activation [7]. Furthermore, NMDAR-mediated ERK activation in turn stimulates CREB, a transcriptional factor which regulates a number of genes critical for long-term neuroprotective effect [12]. A prevalent view has emerged to explain the two opposing effects - excitotoxicity and pro-survival - on neurons upon NMDAR activation: they are mediated by different NMDAR subtypes containing GluN2B and GluN2A, respectively [7].

Many neuroprotective compounds have been demonstrated to be effective in animal models of cerebral ischemia, and some candidates are being actively pursued in clinical trials (e.g. clinical trials with identifiers NCT02315443, NCT02222714, NCT01454154, NCT01221246, NCT01502761, NCT02144584 and NCT02535611), including four that mitigate the excitotoxicity mediated through NMDAR (NCT02315443, NCT01502761, NCT02144584 and NCT02535611), by blocking NMDAR channel current or channel interaction with PSD95 $[6,8,11,13,14]$. It is known that some traditional Chinese medicine (TCM) preparations exert neuroprotection with few or no adverse effects, and some can inhibit NMDAR current $[15,16]$.

According to traditional Chinese medicine, stroke is caused by $Q i$ deficiency and blood stasis [17, 18]. For centuries, various multi-herbal formulas have been used by Chinese medicine practitioners to treat various diseases [19-21]. Based on the theory of TCM, together with modern pharmacological knowledge of herbal medicines, a neuroprotective formula called Post-Stroke Rehabilitation (PSR), comprising seven herbs (Table 1) has been designed. Most chosen herbs have been used in herbal mixtures for stroke treatment, including Buyang Huanwu, Sheng Yu, Xiaoxuming, Gualou Guizhi and Wen Dan Decoctions as well as BNG-1, Hua Tan Tong Luo formula and Nao-Shuan-Tong [22-30]. Moreover, extracts and/or isolates from all constituent herbs have

Table 1 Herbal components of PSR and their implications for stroke treatment

\begin{tabular}{|c|c|}
\hline Component of PSR & Implications for stroke treatment $^{\mathrm{a}}$ \\
\hline $\begin{array}{l}\text { 1. Astragalus membranaceus (Fisch.) } \\
\text { Bunge (Huangqi) }\end{array}$ & $\begin{array}{l}\text { A component of Buyang Huanwu Decoction }{ }^{\mathrm{b}} \text { (BYHWD), Sheng Yu Decoction and BNG-1 [22, 23, 27]; used } \\
\text { with Honghua to treat stroke patients [17]; its isolates, calycosin and formononetin, were neuroprotective in } \\
\text { cerebral ischemic rats }[40,81]\end{array}$ \\
\hline 2. Salvia miltiorrhiza Bunge (Danshen) & $\begin{array}{l}\text { A component of Hua Tan Tong Luo formula and BNG-1 [27-29]; polysaccharide extract and active isolates, } \\
\text { lithospermic acid, salvianolic acid B, cryptotanshinone, tanshinone I and tanshinones IIA-B, could reduce damages } \\
\text { caused by cerebral ischemia in rodents [41, 82-85] }\end{array}$ \\
\hline 3. Paeonia lactiflora Pall. (Chishao) & $\begin{array}{l}\text { A component of BYHWD [22] and Nao-Shuan-Tong [30]; showed proliferative effects on injured rat peripheral } \\
\text { neurons and Schwann cells [31, 32]; an isolate, paeoniflorin, was neuroprotective in cerebral ischemic rats [86] }\end{array}$ \\
\hline 4. Cassia obtusifolia L. (Juemingzi) & $\begin{array}{l}\text { Used for hyperlipidemia treatment [44]; showed neuroprotective effects in hippocampal neurons and in cell and } \\
\text { animal models of Parkinson's disease in mice [33, 34]; an isolate, chrysophanol, showed neuroprotective effect in } \\
\text { ischemic mice [87] }\end{array}$ \\
\hline $\begin{array}{l}\text { 5. Ligusticum chuanxiong Hort. } \\
\text { (Chuanxiong) }\end{array}$ & $\begin{array}{l}\text { A component of BYHW, Sheng Yu, and Xiaoxuming Decoctions [22-24]; butylidenephthalide, ferulic acid and } \\
\text { ligustilide isolated from Chaunxiong were neuroprotective in rodent cells and ischemic rats }[36-38,88]\end{array}$ \\
\hline $\begin{array}{l}\text { 6. Angelica sinensis (Oliv.) Diels } \\
\text { (Danggui) }\end{array}$ & $\begin{array}{l}\text { A component of BYHWD and Sheng Yu Decoction [22, 23]; ferulic acid and ligustilide isolated from Danggui } \\
\text { showed neuroprotection in rodent cells and ischemic rats [36-38] }\end{array}$ \\
\hline 7. Glycyrrhiza uralensis Fisch. (Gancao) & $\begin{array}{l}\text { A component of BNG-1, Xiaoxuming, Gualou Guizhi, and Wen Dan Decoctions [24-27]; used to treat diabetic } \\
\text { acute ischemic stroke [89]; liquiritin, a major constituent, enhanced the neurotrophic effect of NGF [90], showed } \\
\text { protection against Aß-induced toxicity in rat cortical neurons and ischemic mice [35, 91] }\end{array}$ \\
\hline
\end{tabular}

${ }^{a}$ Examples and references shown are selections highlighted by the authors

${ }^{\mathrm{b}}$ Buyang Huanwu, Sheng Yu, Xiaoxuming, Gualou Guizhi, and Wen Dan Decoctions, BNG-1, Hua Tan Tong Luo formula and Nao-Shuan-Tong are herbal mixtures that have been used to treat stroke patients in China

Neuroprotection data obtained from in vitro and animal studies are written in italics 
been demonstrated to be neuroprotective in cell and/or animal models. For examples, extracts from $C$. obtusifolia and G. uralensis could protect cultured neurons against experimental induced-neurotoxicity and P. lactiflora extract could induce proliferation of injured neurons or cultured Schwann cells [31-35]; active molecules such as calycosin isolated from A. membranaceus, tanshinones from S. miltiorrhiza, chrysophanol from C. obtusifolia, and ferulic acid and ligustilide from $L$. chuanxiong and $A$. sinensis were neuroprotective in rodent ischemic models [36-41]. Four of the selected herbal components - A. membranaceus, P. lactiflora, L. chuanxiong and A. sinensis - are among the most commonly used herbs for stroke treatment [42]. In addition to the prominent neuroprotective properties of S. miltiorrhiza, G. uralensis and C. obtusifolia (Table 1), they were included in PSR because $S$. miltiorrhiza, can promote blood circulation and remove blood stasis [43]; G. uralensis can harmonize the actions of multiple herbs [43]; C. obtusifolia has been shown to reduce hyperlipidemia [44, 45], a known risk factor for stroke [45]. The amount of each herb used in the PSR mixture is in accordance with the recommendation stated in the Chinese Pharmacopoeia [43].

To further understand if PSR is an effective treatment for stroke, preclinical and clinical studies are required. In this study, we aim to understand the action mechanism of PSR using in vitro primary embryonic neuron cultures, which express predominately GluN2B-containing NMDA receptors [46], and in vivo using the rat middle cerebral artery occlusion (MCAO) model. Our study indicates that PSR can protect against NMDA-induced excitotoxicity, inhibit NMDA-induced current and activate the pro-survival ERK/CREB signaling in cultured primary embryonic neurons. Furthermore, PSR is neuroprotective and attenuates neurological impairments in MCAO rats when administered either before or after the onset of ischemia. The present findings offer insights into the underlying multi-targeted neuroprotective mechanism of PSR and provide a scientific basis for its further pharmacological development for managing stroke and other neurological diseases.

\section{Methods}

\section{Chemicals and reagents}

Unless otherwise specified, all chemicals, antibodies, and culture reagents were purchased from Sigma (MO, USA), Cell Signaling Technology (MA, USA), and Life Technologies (CA, USA), respectively.

\section{Animals and the MCAO model}

Sprague-Dawley (SD) rats were obtained and reared from the Animal and Plant Care Facility of The Hong Kong University of Science and Technology. Rats were provided with food and water ad libitum under a 12/12 h light/dark cycle. Transient focal cerebral ischemia was induced by intra-luminal MCAO as described previously [47, 48]. Male SD rats (280-320 g) were anesthetized and placed on heating pad to maintain rectal temperature at $37^{\circ} \mathrm{C}$. A nylon filament was advanced from the right external carotid artery into the lumen of the internal carotid artery to occlude the right MCA for $2 \mathrm{~h}$, and the filament was subsequently withdrawn to allow reperfusion. The cerebral blood flow of the rats was monitored closely with Laser Doppler (PF 5010 - LDPM unit; PERIMED) during the operation. Sham-treated rats were subjected to the same operative procedure without the insertion of the nylon filament. The right femoral artery was cannulated to monitor arterial blood gases, $\mathrm{pH}$, electrolytes, and hematocrit. All procedures were approved by the Animal Ethics Committee of The Hong Kong University of Science and Technology.

\section{Plant collection and identification}

PSR comprises A. membranaceus, S. miltiorrhiza, P. lactiflora, C. obtusifolia, L. chuanxiong, A. sinensis, and G. uralensis (Table 1). All herbs were purchased from Lee Hoong Kee Limited, Hong Kong, and collected from different regions of China: A. membranaceus (roots; voucher ID: TCM208-4) and G. uralensis (roots and rhizomes; TCM080-4) from Inner Mongolia Autonomous Region; S. miltiorrhiza (roots and rhizomes; TCM012-4), P. lactiflora (roots; TCM037-3) and L. chuanxiong (rhizomes; TCM111-3) from Sichuan; C. obtusifolia (seeds; TCM238-2) from Anhui; A. sinensis (roots; TCM800-2) from Gansu. All herbs were authenticated by one of the authors (Dr. Guang-Miao Fu, a pharmacognosist) and a voucher specimen of each herb with identification number indicated above was deposited in the herbarium of the Biotechnology Research Institute at the Hong Kong University of Science and Technology.

\section{PSR preparation and HPLC fingerprinting}

The PSR formula was prepared by the National Engineering Research Center for Modernization of Traditional Chinese Medicine, Zhuhai, China. The amount of each herb used in the mixture is in accordance with the recommendation stated in the Chinese Pharmacopoeia [43]. Briefly, mixture containing A. membranaceus (15 g), S. miltiorrhiza (10 g), P. lactiflora (7.5 g), C. obtusifolia (7.5 g), L. chuanxiong (6 g), A. sinensis (6 g), G. uralensis (6 g) were refluxed with water (w/v 1:8) for $1 \mathrm{~h}$. The extracts collected were cooldried by vacuum into a brown powder. Two batches of extract were prepared and the yields were $\sim 18 \%$, respectively. The powder was used for in vitro and in vivo studies. An HPLC-diode array detection system (Waters) was used for fingerprint analysis. Each filtered sample $(20 \mu \mathrm{L})$ was separated on a C18 column with a mixture of acetonitrile 
and $0.1 \%$ trifluoroacetic acid in water at room temperature; a gradient elution of acetonitrile from 10$90 \%$ was applied. Eluents were monitored by the absorbance at $254 \mathrm{~nm}$.

\section{PSR administration}

PSR dissolved in water was orally administered to rats before and after MCAO. The human-equivalent dose (HED) in rats was calculated to be $1.1 \mathrm{~g} / \mathrm{kg}$. Rats were dosed with 1.1, 2.2 and $5.5 \mathrm{~g} / \mathrm{kg}$ and the dosing volume was $5.5 \mathrm{~mL} / \mathrm{kg}$. For the pre-treatment regimen, PSR was administered daily for 5 days before and 6, 24, and $48 \mathrm{~h}$ after MCAO onset. For the post-treatment regimen, PSR was administered 6, 24 h, and then daily after MCAO onset. Deionized water was administered as control.

\section{Evaluation of neurological deficit}

Bederson's neurological examination scoring system [49, 50] was used to evaluate neurological deficit. Rats were scored 0 if they had no observable deficit (normal); 1 if they failed to fully extend the left forepaw (mild deficit); 2 if they circled towards the contralateral side (moderate deficit); and 3 if they lost the ability to walk and righting reflexes (severe deficit).

\section{Measurement of cerebral infarction and edema extent}

After the final evaluation of neurological deficit, rats were sacrificed and their brains were removed, fixed with $4 \%$ paraformaldehyde, sectioned into seven 2-mm coronal slices, and stained with $2 \%$ (w/v) 2,3,5-triphenyltetrazolium chloride (TTC) for $30 \mathrm{~min}$ at $37{ }^{\circ} \mathrm{C} \mathrm{[49].}$ Images of the slices were taken and analyzed using ImageJ System software (National Institutes of Health, Bethesda, MD). The infarct area in each slice was determined by subtracting the TTC-stained area in the ipsilateral (i.e., ischemic) hemisphere from that of the contralateral (i.e., non-ischemic) hemisphere and expressed as the percentage of the TTC-stained area of the contralateral hemisphere. Infarct volume was calculated on the basis of the infarct area and slice thickness. The ischemiainduced gain in hemispheric volume (i.e., edema) was calculated by subtracting the volume of the contralateral hemisphere from that of the ipsilateral hemisphere and expressed as the percentage of the volume of the contralateral hemisphere.

\section{Primary neuronal cultures}

Embryonic cortical and hippocampal neurons express high levels of GluN2B-containing NMDA receptors and therefore were used for this study [46]. They were prepared from embryonic day 18 (E18) SD rats as described previously [51]. Cortical neurons were cultured on poly-D-lysine-coated plates and maintained in neurobasal medium supplemented with $2 \%$ B-27 supplement, penicillin (100 units/mL), and streptomycin $(100 \mu \mathrm{g} /$ $\mathrm{mL}$ ) at $37{ }^{\circ} \mathrm{C}$ in a humidified atmosphere with $5 \% \mathrm{CO}_{2}$. Hippocampal neurons were grown similarly, except the medium was supplemented with $0.5 \mathrm{mM}$ L-glutamine.

\section{NMDA excitotoxicity assay and immunohistochemistry}

Since a larger quantity of cortical neurons can be obtained from one embryo compared to hippocampal neurons, cortical neurons were used for NMDA excitotoxicity assay. Cortical neurons at 11-12 days in vitro (DIV) were pre-treated with PSR or vehicle (DMSO) for $2 \mathrm{~h}$ and subsequently rinsed with Locke's solution $(5 \mathrm{mM} \mathrm{KCl}$, $128 \mathrm{mM} \mathrm{NaCl}, 2.7 \mathrm{mM} \mathrm{CaCl}, 1 \mathrm{mM} \mathrm{Na} \mathrm{HPO}_{4}, 5 \mathrm{mM}$ HEPES, and $10 \mathrm{mM}$ glucose) followed by a $15-\mathrm{min}$ incubation with glycine-containing $(10 \mu \mathrm{M})$ Locke's solution. The neurons were then co-treated with PSR (or vehicle) and $20 \mu \mathrm{M}$ NMDA dissolved in Locke's plus glycine solution for $20 \mathrm{~min}$. The neurons were then incubated with fresh growth medium. After $24 \mathrm{~h}$, NMDA excitotoxicity was assessed by either the lactate dehydrogenase (LDH) release assay (Roche) or immunohistochemistry, as described previously [52]. The cell death in the presence of PSR and NMDA was quantified by normalizing the LDH release to the maximum (vehicle with NMDA, the control) and minimum (no NMDA) LDH releases. Neurons were immunostained with $\beta$-tubulin type III antibody (1:1000, Sigma) and labeled with FITC-conjugated secondary antibody. DAPI (4', 6-diamidino-2-phenylindole) was used to stain the nuclei. Images were captured and visualized by fluorescent microscopy (Leica).

\section{Electrophysiology}

Embryonic hippocampal neurons express larger NMDAR current compared to cortical neurons and were used for patch clamp recording of the NMDAR current. Wholecell recording was performed at room temperature $\left(\sim 22{ }^{\circ} \mathrm{C}\right)$ as previously described $[51,53]$. The pipette solution contained (in mM): $135 \mathrm{CsCl}$, 0.5 EGTA, $2 \mathrm{MgCl}_{2}, 4$ $\mathrm{Na}_{2} \mathrm{ATP}, 0.4 \mathrm{NaGTP}$, and 10 HEPES ( $\mathrm{pH} 7.25$ ). The bath solution contained (in $\mathrm{mM}$ ): $5.3 \mathrm{KCl}, 0.4 \mathrm{KH}_{2} \mathrm{PO}_{4}, 4.2$ $\mathrm{NaHCO}_{3}, 138 \mathrm{NaCl}, 0.3 \mathrm{Na}_{2} \mathrm{HPO}_{4}$, and 27.8 glucose, 2.5 $\mathrm{CaCl}_{2}, 0.01$ glycine, 0.0005 tetrodotoxin, 0.02 bicuculline methiodide (Tocris), and 5 HEPES (pH 7.4). NMDA alone $(20 \mu \mathrm{M})$ or with PSR were added to the bath solution. Pipettes were fire-polished, and resistance was 3-5 M $\Omega$. Currents were recorded at $-70 \mathrm{mV}$ using a Multiclamp $700 \mathrm{~B}$ amplifier and data were analyzed using pClamp 10 (Molecular Devices, USA).

\section{Western blotting}

After treatment, cortical neurons were lysed with RIPA buffer at different time points. Western blot analysis was performed as described previously [54]. Briefly, protein samples $(30 \mu \mathrm{g})$ were separated by SDS-PAGE and then 
transferred to nitrocellulose membrane, which was subsequently incubated with antibodies specific to phosphop44/42 mitogen-activated protein kinase (p-ERK) (1:1000), p44/42 mitogen-activated protein kinase (ERK) (1:1000), phospho-cAMP response element-binding protein (pCREB) (1:1000), or CREB (1:1000). The membranes were then washed and incubated with horseradish peroxideconjugated secondary antibody (1:2000). Signals were detected using the SuperSignal West Pico chemiluminescent substrate kit (Pierce, Rockford, IL, USA). Band densitometry was measured and analyzed by ImageJ.

\section{Luciferase reporter assay}

Freshly isolated cortical neurons were transiently transfected with the luciferase reporter construct (CRE-Luc) [55] using Lipofectamine 2000. Transfected neurons (9-11 DIV) were treated with PSR or vehicle (DMSO) for $6 \mathrm{~h}$ and then lysed with luciferase lysis buffer. Lysates were transferred onto white-bottom plates and assessed using a luciferase assay kit (Promega). Luciferase (i.e., CRE) activity was quantified using a Promega GloMax ${ }^{\text {Tw }} 96$ microplate luminometer.

\section{Statistical analysis}

Results are reported as mean \pm SEM (or SD if number of experiments is 2). Data with two dependent variables (e.g. drug dose and time/coronal slice) were analyzed by two-way ANOVA followed by Bonferroni post-test; data with one dependent variable were analyzed by one-way ANOVA followed by Newman-Keuls post-test, except when stated otherwise. The level of significance was indicated by ***, and **** which corresponds to $P<0.05$, $<0.01$, and $<0.0,01$, respectively.

\section{Results}

\section{HPLC fingerprinting of PSR extracts}

To analyze the major chemical components in the extracts and to assess the quality of extracts obtained from different batches, samples of PSR were analyzed by HPLC. A typical chromatogram of a PSR preparation is presented in Fig. 1. By comparing their retention times and UV spectra to those of the standards, 12 chromatographic peaks were identified (Table 2). These 12 compounds encompass the known chemical markers from all the seven herbs in PSR, and they contribute to the major chemical composition of the decoction. The quality of the PSR extracts was routinely monitored and only extracts containing these 12 peaks in the chromatograms were used in our experiments.

\section{PSR attenuates NMDA excitotoxicity and reduces NMDA- induced current in primary cortical neurons}

All the signature compounds of PSR, except ononin (Table 2), have been demonstrated to be neuroprotective in rodent models of cerebral ischemia, and ononin can protect neuronal cells against glutamate-induced cytotoxicity [32, 34, 50-58]. Therefore, it is likely that PSR extract prepared from our formula can exert neuroprotection. To investigate whether PSR extract is neuroprotective in vitro, we employed primary cortical neurons that have been insulted with NMDA to induce excitotoxicity. E18 cortical neurons were treated with PSR extract for $2 \mathrm{~h}$ followed by a 20-min co-incubation with a toxic dose of NMDA $(20 \mu \mathrm{M})$. Immunostaining was performed $24 \mathrm{~h}$ after NMDA challenge. DAPI and $\beta$ tubulin type III staining were used to indicate nuclei and neurite networks in neuronal cultures, respectively. Cortical neurons insulted by NMDA exhibited shrunken cell bodies with sparse neurites (Fig. 2a). PSR $500 \mu \mathrm{g} / \mathrm{mL}$ treatment largely restored the intact neurite network in NMDA-challenged neurons (Fig. 2a). When cell death was quantified by LDH assay, a dose-dependent protective effect of PSR on NMDA-treated cells was revealed. PSR 500 to $1000 \mu \mathrm{g} / \mathrm{mL}$ treatment significantly reduced NMDA-induced cell death in primary cortical neurons (Fig. 2b). These findings demonstrate that PSR effectively protects cortical neurons against NMDAinduced excitotoxicity.

The calcium current induced by NMDA in hippocampal neurons contributes to its excitotoxicity [56]. To determine if PSR affects NMDA-evoked current, whole-cell patch-clamp recording was conducted on hippocampal neurons. PSR and NMDA co-administration resulted in reduced current (Fig. 2c). PSR $500 \mu \mathrm{g} / \mathrm{mL}$ significantly

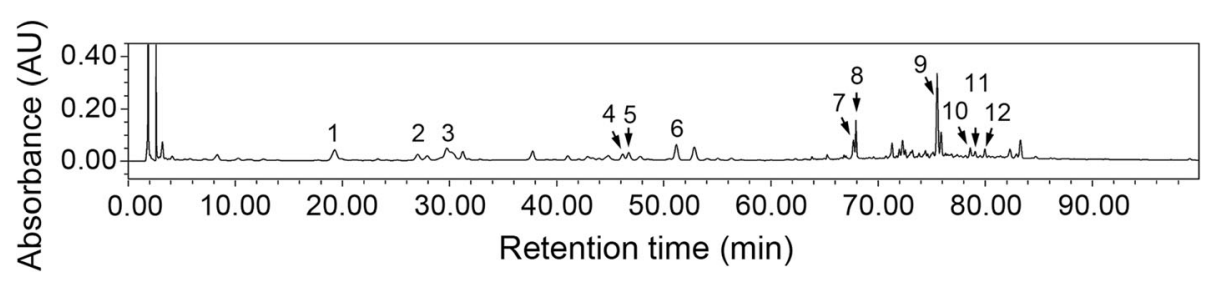

Fig. 1 The HPLC chromatographic fingerprint of PSR. A typical chromatogram contains 12 peaks representing chemical markers of different component herbs in PSR. The 12 peaks were identified by comparing their retention times and UV spectra with those of the standards (Table 2). The presence of these 12 compounds indicates that each component herb in PSR contribute to the chemical composition of the extract 
Table 2 Identities and abundances of the 12 marker compounds corresponding to peaks 1-12 in the chromatogram of PSR shown in Fig. 1

\begin{tabular}{|c|c|c|c|c|}
\hline Peak & Marker $^{a}$ & $\begin{array}{l}\text { Retention time } \\
\text { (min) }\end{array}$ & $\begin{array}{l}\text { Abundance } \\
\text { (\%) }\end{array}$ & $\begin{array}{l}\text { Herbs indicated } \\
\text { by the marker }\end{array}$ \\
\hline 1 & Paeoniflorin & 20.20 & $15.95 \pm 0.94$ & P. lactiflora \\
\hline \multirow[t]{2}{*}{2} & \multirow[t]{2}{*}{ Ferulic acid } & \multirow[t]{2}{*}{28.57} & \multirow[t]{2}{*}{$0.51 \pm 0.04$} & A. sinensis \\
\hline & & & & L. chuanxiong \\
\hline 3 & Liquiritin & 31.20 & $0.43 \pm 0.05$ & G. uralensis \\
\hline 4 & Ononin & 45.78 & $0.16 \pm 0.01$ & $\begin{array}{l}\text { A. } \\
\text { membranaceus }\end{array}$ \\
\hline 5 & Lithospermic acid & 48.19 & $0.64 \pm 0.02$ & S. miltiorrhiza \\
\hline 6 & Salvianolic acid B & 52.67 & $1.62 \pm 0.04$ & S. miltiorrhiza \\
\hline 7 & Glycyrrhizic acid & 68.14 & $1.41 \pm 0.04$ & G. uralensis \\
\hline 8 & Formononetin & 68.45 & $0.53 \pm 0.01$ & $\begin{array}{l}\text { A. } \\
\text { membranaceus }\end{array}$ \\
\hline \multirow[t]{2}{*}{9} & \multirow[t]{2}{*}{ Ligustilide } & \multirow[t]{2}{*}{75.76} & \multirow[t]{2}{*}{$0.25 \pm 0.00$} & A. sinensis \\
\hline & & & & L. chuanxiong \\
\hline 10 & Cryptotanshinone & 78.78 & $0.25 \pm 0.02$ & S. miltiorrhiza \\
\hline 11 & Tanshinone I & 79.39 & $3.81 \pm 0.21$ & S. miltiorrhiza \\
\hline 12 & Chrysophanol & 80.18 & $0.52 \pm 0.01$ & C. obtusifolia \\
\hline
\end{tabular}

${ }^{a}$ All the marker compounds of PSR except ononin have been demonstrated to be neuroprotective in rodent models of cerebral ischemia, and ononin can protect neuronal cells against glutamate-induced cytotoxicity $[32,34,50-58]$

reduced the mean steady state currents by $49 \pm 3 \%$ compared to the control (Fig. 2d). A $5 \mathrm{~s}$ wash-out restored the NMDA-induced current to the control level, indicating that PSR reversibly inhibits NMDAR current with a relative fast off-rate.

\section{PSR activates ERK/CREB signaling in primary cortical neurons}

ERK activation has been implicated in protecting neurons against apoptosis [57, 58]. CREB, a transcription factor involved in neuroprotection, learning, and memory, is activated downstream of ERK [59, 60]. To determine whether PSR can activate ERK and CREB, primary cortical neurons were treated with PSR $500 \mu \mathrm{g} / \mathrm{mL}$ and the phosphorylation levels of ERK and CREB were investigated. Western blotting revealed that ERK phosphorylation had already maximally increased after 5 min of treatment and was maintained at this high level for up to $15 \mathrm{~min}$ of treatment, decreasing gradually thereafter to a level still slightly higher than that of the control (band intensities were compared at 0 and $180 \mathrm{~min}$ of treatment; Fig. 3a, b). On the other hand, a persistent increase in CREB phosphorylation was observed, and at $180 \mathrm{~min}$ of treatment, the increase in CREB phosphorylation was significant. To verify the activation of CREB, the effect of PSR on CRE-promoter was examined in primary cortical neurons transiently expressing a CRE-driven luciferase reporter.
Compared to the control, incubation with PSR 500$1000 \mu \mathrm{g} / \mathrm{mL}$ significantly activated CRE promoter, as indicated by the increase in luciferase activity (Fig. 3b). Taken together, these results suggest that PSR may enhance the survival of neurons by potentiating the pro-survival ERK and CREB signaling.

\section{PSR pre-treatment reduces functional deficit and ischemic} injury in MCAO rats

Given the in vitro data showing PSR could activate prosurvival ERK and CREB signaling, inhibit NMDAR current and counteract NMDA-induced neuronal excitotoxicity, we explored whether PSR is neuroprotective against ischemic brain injury using the rat transient MCAO model (i.e., $2 \mathrm{~h}$ occlusion followed by reperfusion) [50]. We began by examining if PSR could reduce acute ischemic injury by using a pre-treatment regimen. MCAO strongly affected neural behavior as indicated by the neurological scores of the vehicle control groups measured at 24, 48 and $72 \mathrm{~h}$ after MCAO (score $>2$; Fig. 4a). Significant improvements (i.e., decreases) in neurological scores were observed in rats treated with PSR at all dosages tested at $24 \mathrm{~h}$ and the improvements were maintained at 48 and $72 \mathrm{~h}$. The cerebral infarct area and volume were also reduced in PSR-treated rats (Fig. 4b, c and Additional file 1: Figure S1 in supplemental information). The extent of edema was reduced in PSR-treated rats, although the difference was not statistically significant when compared to the control (Fig. 4d). These data indicate that pre-treating rats with PSR can effectively reduce the functional deficit and cerebral infarct induced by MCAO. The physiological parameters of the rats were closely monitored throughout the experiments, and no differences were found after PSR administration with respect to mean $\mathrm{pH}, \mathrm{PaCO}_{2}, \mathrm{PaO}_{2},\left[\mathrm{HCO}_{3}^{-}\right]$, or [Hb] (Additional file 1: Table S1).

\section{PSR post-treatment attenuates functional deficit and is- chemic injury}

In order to investigate the therapeutic efficacy of PSR against acute stroke in a more clinically relevant setting, PSR was administered 6, 24 and $48 \mathrm{~h}$ after MCAO onset (post-treatment regimen). Rats post-treated with PSR at all given doses exhibited significant improvements in neurological scores measured 24, 48, and $72 \mathrm{~h}$ after MCAO (Fig. 5a); the greatest improvement was achieved with PSR $1.1 \mathrm{~g} / \mathrm{kg}$. Consistent with the improvement in neural behavior, there were overall reductions in infarct area and volume in MCAO rats post-treated with PSR (Fig. 5b, c and Additional file 1: Figure S2). The extent of edema was reduced in PSR-treated rats, although not statistically significant (Fig. 5d). As neurological impairment is a major long-term complication in stroke patients, we evaluated if PSR can attenuate the devastating 


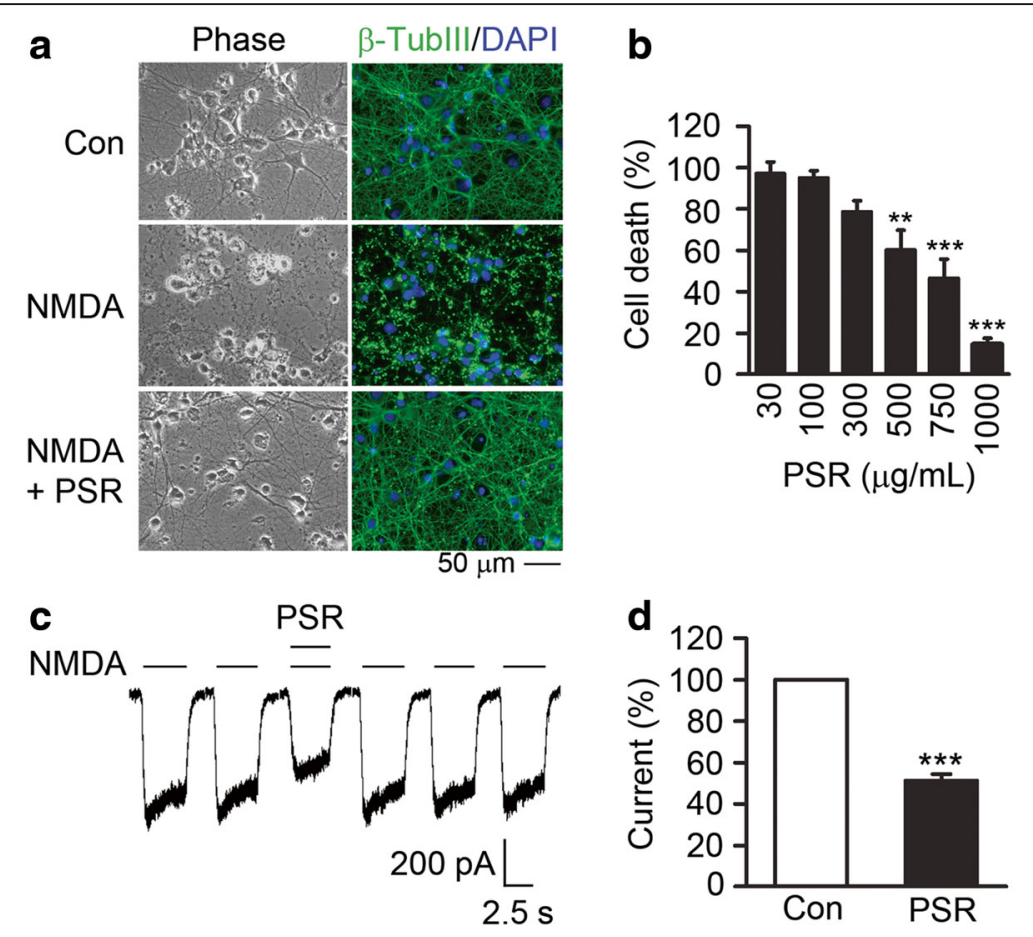

Fig. 2 PSR protects neurons against NMDA excitotoxicity. a Rat cortical neurons were treated with vehicle (top panels), 20 HM NMDA (middle panels), or $20 \mu \mathrm{M}$ NMDA plus PSR $500 \mu \mathrm{g} / \mathrm{mL}$ (bottom panels). Phase contrast images are shown on the left. The right panels show the overlay of the DAPI- and $\beta$-tubulin III-stained images. $\mathbf{b}$ LDH released from NMDA-challenged neurons with or without PSR treatment was measured and quantified as normalized cell death (see Methods). Four concentration-response experiments, with each concentration of PSR conducted in duplicate wells, were performed. For PSR 30, 750 and $1000 \mu \mathrm{g} / \mathrm{mL}$, number of data points $(\mathrm{n})=2$; for PSR 100, 300 and $500 \mu \mathrm{g} / \mathrm{mL}$, $n=4$. Statistical significance between PSR-treated and control groups was analyzed by one-way ANOVA followed by Newman-Keuls post-test. c Representative whole-cell currentresponse recorded from a hippocampal neuron. NMDA-induced current was reversibly inhibited by PSR $500 \mu \mathrm{g} / \mathrm{mL}$. d Inhibitory effect of PSR $500 \mu \mathrm{g} /$ $\mathrm{mL}$ on NMDA-induced current. The control was the NMDA-induced current level in the absence of PSR (set as $100 \%)$. Statistical significance was analyzed by paired t-test $(n=4)$

long-term consequences of behavioral impairment in MCAO rats. In this experiment, rats were post-treated with PSR $1.1 \mathrm{~g} / \mathrm{kg}$ for up to 4 weeks and the subsequent neurological functions were examined once weekly. Compared to the control rats, PSR significantly improved the neurological scores of rats at 7 and 14 days after MCAO (Fig. 5e). Taken together, these data demonstrate that PSR post-treatment can effectively alleviate ischemic injury and behavioral deficit in rats after cerebral ischemia.
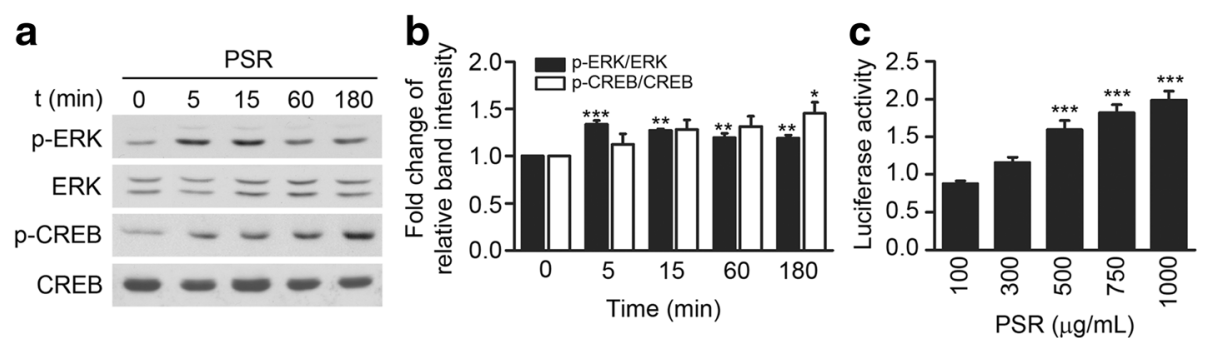

Fig. 3 Activation of ERK and CREB by PSR. a Western blots and quantitative densitometry (b) showing the effect of 0-180 min of PSR 500 $\mu \mathrm{g} / \mathrm{mL}$ treatment on ERK and CREB phosphorylation. Band intensities in western blots $(n=2)$ were quantified using ImageJ. The band intensity of the phosphorylated ERK/CREB protein is first normalized to that of the corresponding total ERK (or CREB) protein, and then the value of the normalized band intensity of the phosphorylated protein at time 0 was set as 1 . Statistical significance in (b) was performed by one-way ANOVA followed by Newman-Keuls post-test to compare the band intensity at each time point to that of time 0 . $\mathbf{c}$ Effect of 6 h-treatment of PSR on the luciferase activity of neurons transfected with the CRE-Luc construct. Seven concentration-response experiments, with each concentration of PSR conducted in duplicate wells, were performed. For PSR 100 to $1000 \mu \mathrm{g} / \mathrm{mL}, n=5,6,7,7,4$, respectively. Statistical significance between PSR-treated and control groups was analyzed by one-way ANOVA followed by Newman-Keuls post-test 


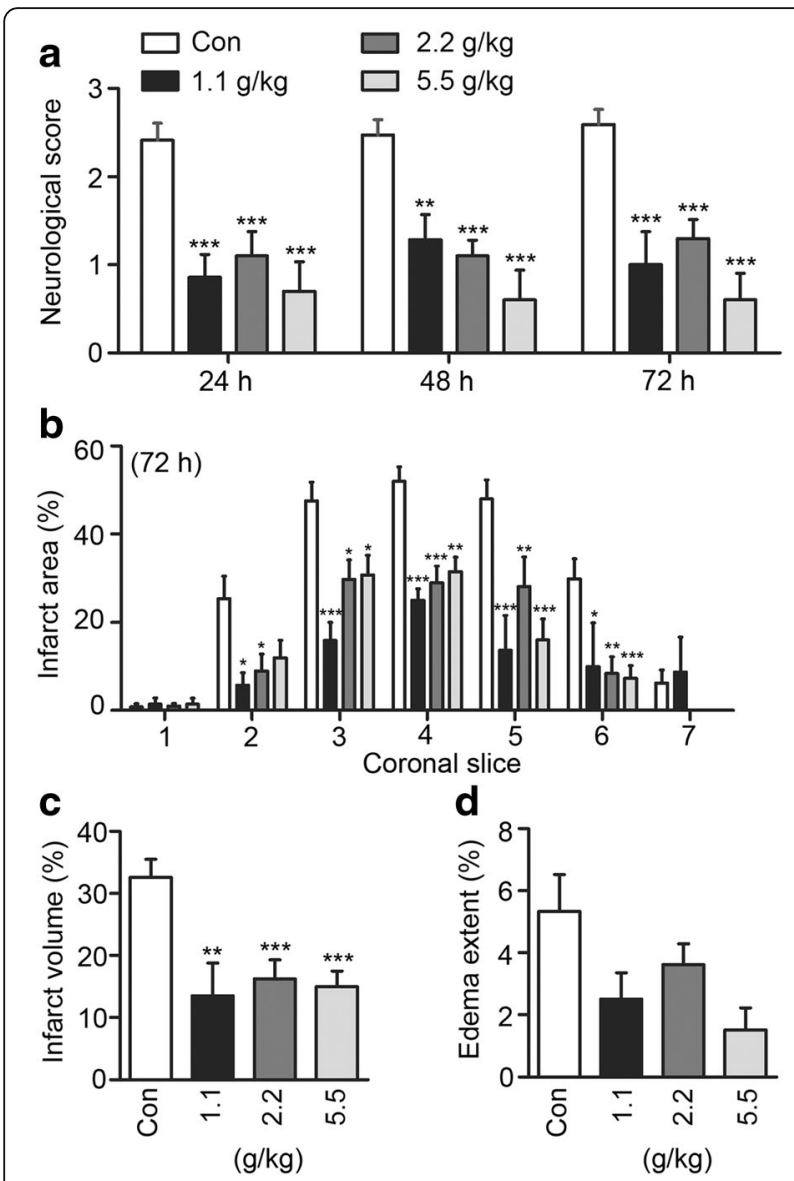

Fig. 4 PSR pre-treatment reduces neurological deficit and cerebral infarct in MCAO rats. a Rats were pre-treated with vehicle (con) or different doses of PSR, and neurological scores were determined 24, 48 , and $72 \mathrm{~h}$ after MCAO. Infarct area (b), infarct volume (c), and edema content (d) were measured $72 \mathrm{~h}$ after MCAO. For $(\mathbf{a}-\mathbf{c})$, the numbers of animals in the control, PSR 1.1, 2.2 and $5.5 \mathrm{~g} / \mathrm{kg}$ groups were $17,7,10$ and 10, respectively. For (D), $n$ for control $=14$. In (a, b), statistical significance between PSR-treated and control groups was analyzed by two-way ANOVA followed by Bonferroni post-test. For infarct area, the $P$-values of the differences between treatment groups and the corresponding controls of the same coronal slices are shown. In (c, d), statistical significance between PSR-treated and control groups was analyzed by one-way ANOVA followed by NewmanKeuls post-test. The key pattern shown in (a) applies to all other panels in this figure as well as in Fig. 5

\section{Discussion}

PSR is a novel neuroprotective formula designed for stroke treatment. Its constituent herbs have all been demonstrated with prominent neuroprotective properties. The further development of PSR for stroke treatment relies on both preclinical and clinical studies. The work reported here is a pioneer preclinical study of PSR demonstrating its neuroprotective efficacy. We first demonstrated that PSR extract could prominently attenuate cell death using cultured NMDA challenged-neurons. This in vitro finding validate the neuroprotective character of the selected herbal components of PSR. Furthermore, it indicate that the net activity of all the neuroprotective compounds within the PSR extract persists despite possible neutralizing interactions that can occur with the many other molecules presence in the extract. Support by the in vitro data, PSR was tested in vivo using MCAO rats, and demonstrated to be effective in reducing cerebral injury and improving neural behavior. Further in vitro studies on the effects of PSR on NMDAR currents and ERK and CREB activation shed insights into its mechanism of action.

Our in vivo study demonstrates that PSR pre- and even post-treatments can effectively decrease ischemic infarct size and reduce functional neurological impairment in MCAO rats. The effectiveness of pre-treatment suggests that PSR may be developed for the prophylactic management of patients with a high risk of stroke recurrence [61]. Two aspects of the present post-treatment data are particularly outstanding. First, PSR acts quickly to mediate neuroprotection and elicits sustained improvement in neurological function in MCAO rats. Improvements in neurological scores were observed as early as $18 \mathrm{~h}$ after the first dose of PSR and extended up to day 14. Second, the therapeutic time window of PSR in rats is at least $6 \mathrm{~h}$ after the onset of MCAO, which is longer than many other tested compounds/drugs in similar animal models. As patients with stroke onset longer than $3 \mathrm{~h}$ before therapeutic intervention can be practically applied is common, the $6 \mathrm{~h}$ therapeutic time window of PSR in MCAO rats increases the chance of PSR to be successfully translated to human stroke patients $[14,62]$.

Our in vitro finding that PSR can reversibly inhibit NMDA-induced currents with a fast off-rate provides one possible mechanism underlying the neuroprotective effect of PSR. A fast off-rate is a desirable pharmacological property of an NMDAR current inhibitor critical for safety $[11,53]$, and the fast off-rate of PSR is consistent with the long safety history of the herbal components of PSR to treat humans. In contrast to memantine, another NMDAR blocker with fast off-rate failed to protect against ischemic impairment in rat when administered $1 \mathrm{~h}$ after the onset of MCAO [47], the superior therapeutic effect of PSR when administered $6 \mathrm{~h}$ after ischemia suggests that mechanisms other than NMDAR current inhibition is involved in mediating its potent neuroprotective effect.

Increasing evidence shows that single-targeted drug candidates are ineffective for stroke treatment [63]. As TCM formulas contain multiple herbs designed and assumed to act synergistically [19-21], their pharmacological actions are usually multi-targeted. PSR indeed has multiple targets - in addition to inhibiting NMDARmediated current, PSR can activate ERK and CREB, which 

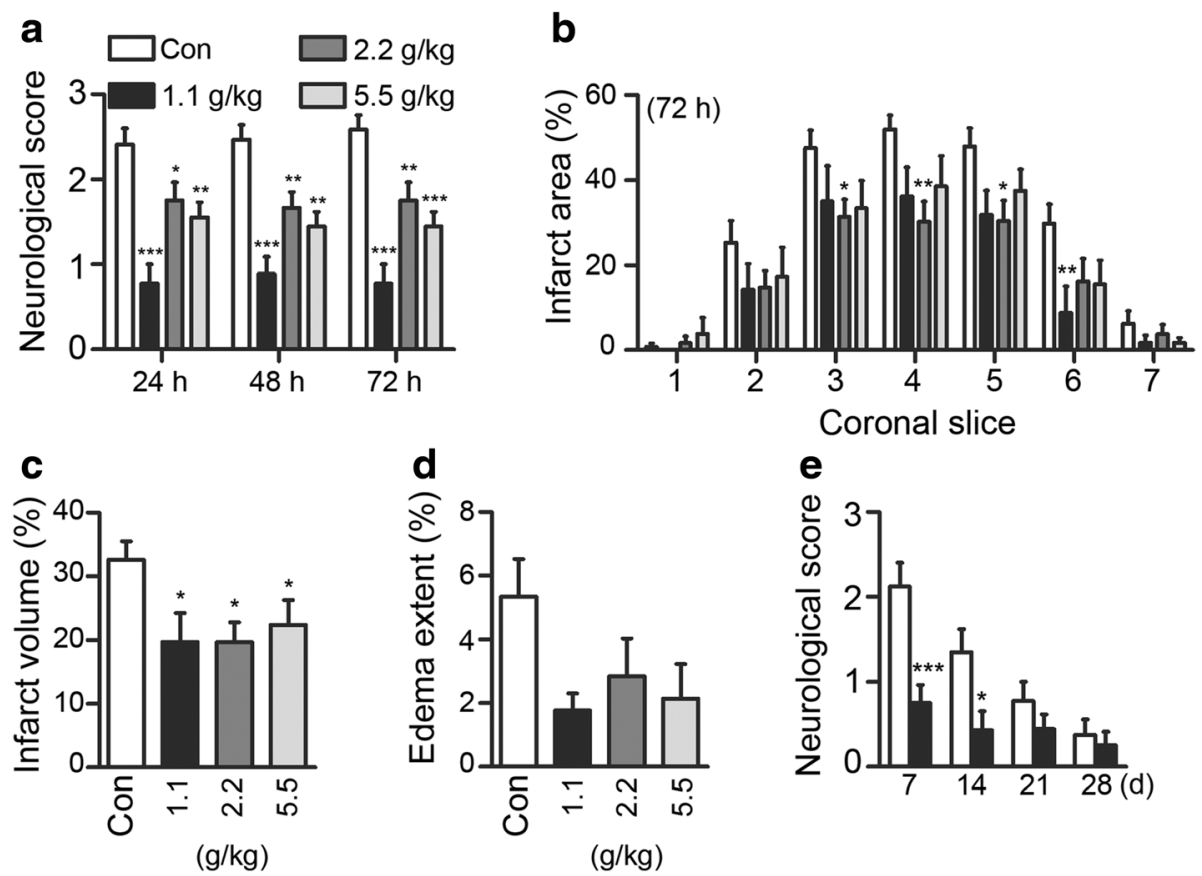

Fig. 5 PSR post-treatment reduces neurological deficit and cerebral infarct in MCAO rats. a Rats were post-treated with vehicle (con) or different doses of PSR, and neurological scores were determined 24, 48, and $72 \mathrm{~h}$ after MCAO. Infarct area (b), infarct volume (c), edema content (d) were measured $72 \mathrm{~h}$ after MCAO. e Adult rats were post-treated with vehicle (con) or PSR $1.1 \mathrm{~g} / \mathrm{kg}$ for up to $28 \mathrm{~d}$ after MCAO. Neurological scores measured at 7, 14, 21, and $28 \mathrm{~d}$ after MCAO are shown. For (a-c), the numbers of animals in the control, PSR 1.1, 2.2 and $5.5 \mathrm{~g} / \mathrm{kg}$ groups were 17, 9, 12 and 9, respectively. For $(\mathbf{d}), \mathrm{n}$ for control $=13$. For $(\mathbf{e})$, the numbers of animals for control and PSR $1.1 \mathrm{~g} / \mathrm{kg}$ groups at day 7, 14, 21 and 28 were 17, 17, 9, 8 and $16,14,9,8$, respectively. In $(\mathbf{a}, \mathbf{b})$ and $(\mathbf{e})$, statistical significance between PSR-treated and control groups was analyzed by two-way ANOVA followed by Bonferroni post-test, respectively. In (c-d), statistical significance between PSR-treated and control groups was analyzed by one-way ANOVA followed by Newman-Keuls post-test

may potentiate the expression of CREB-mediated genes such as growth factors and anti-apoptotic proteins to exert neuroprotective effects [64-67]. Two of the constituent herbs, A. sinensis and L. chuanxiong, have been demonstrated or implicated in activating CREB - pretreatment of cortical neuron culture with extract of $A$. sinensis prevented the reduction of phospho-CREB induced by amyloid beta peptide, and extract of $L$. chuanxiong induced CREB phosphorylation in PC12 cells $[68,69]$. However, to the best of our knowledge, no decoction has been reported to enhance ERK and CREB signaling in cultured primary neurons. Only until recently, a decoction of thirteen herbs to treat memory impairment of schizophrenia patient was shown to activate ERK and CREB in hippocampi of treated animals [70]. Moreover, PSR likely acts on other targets in addition to NMDAR and ERK/CREB, as all its seven constituent herbs except $C$. obtusifolia have been implicated to have both anti-oxidative and antiinflammatory effects, while C. obtusifolia has been implicated to have only anti-inflammatory effect [71-77]. In future experiments, it will be important to demonstrate the anti-oxidative and anti-inflammatory effects of PSR extract, and explore other plausible mechanisms that can contribute to its neuroprotective effect.
There are two possible directions regarding the further development of PSR. First, the PSR extract, although a complex molecular mixture, can be further investigated and developed for stroke treatment. Such effort requires the preparation of a quality-controlled extract from the seven constituent herbs, which in turn relies on standardized good practice to ensure the use of high quality herbs, a consistent procedure for extract preparation and chemical profiling to validate the quality the extract [78, 79]. Alternatively, the extract can be simplified by systematically purifying molecular fractions from the seven herbs, identifying the active molecules, and mixing the active molecules in optimized molar ratio to generate a cocktail which can achieve the best neuroprotective effects. The optimized molar ratio of the active molecules can be derived by using computational algorithm coupled to bioassays [80].

\section{Conclusions}

Extract of PSR, a novel Chinese herbal formula, is neuroprotective in cultured neurons and is effective in reducing ischemic injury in MCAO rats in both the pre- and posttreatment regimens, and the underlying neuroprotective mechanisms may involve inhibition of NMDA receptor 
current and activation of ERK and CREB. As neuroprotection strategies continue to show promise in the treatment of ischemic and hemorrhagic types of strokes, our study provides the scientific basis and critical preclinical data for further development of PSR for stroke treatment.

\section{Additional files}

Additional file 1: Table S1. Assessments of physiological parameters before, during and after ischemia (MCAO) in control and PSR pre-treated rats. Figure S1. Representative TTC-stained brain slices for sham and MCAO rats, with the latter animals divided into 4 groups that were pre-treated with vehicle, $1.1 \mathrm{~g} / \mathrm{kg}, 2.2 \mathrm{~g} / \mathrm{kg}$ or $5.5 \mathrm{~g} / \mathrm{kg}$ PSR. Figure S2. Representative TTCstained brain slices for sham and MCAO rats, with the latter animals divided into 4 groups that were post-treated with vehicle, $1.1 \mathrm{~g} / \mathrm{kg}, 2.2 \mathrm{~g} / \mathrm{kg}$ or $5.5 \mathrm{~g} / \mathrm{kg}$ PSR. (DOCX $3065 \mathrm{~kb}$ )

Additional file 2: An excel file containing all the data used for plotting the bar charts. (XLSX $14 \mathrm{~kb}$ )

\section{Abbreviations}

ANOVA: Analysis of variance; ATP: Adenosine 5'-triphosphate; CREB: CAMP response element binding protein; DAPI: 4',6-diamidino-2-phenylindole; DMSO: Dimethyl sulfoxide; EGTA: Ethylene glycol-bis (2-aminoethylether)N,N,N',N'-tetraacetic acid; ERK: Extracellular signal-regulated kinase; FDA: Food and drug administration; GABA: Gamma-aminobutyric acid; GTP: Guanosine-5'-triphosphate; HEPES: 4-(2-Hydroxyethyl) piperazine-1ethanesulfonic acid; HPLC: High performance liquid chromatography; LDH: Lactate dehydrogenase; MCAO: Middle cerebral artery occlusion; NMDAR: N-methyl-D-aspartate receptor; PSD95: Postsynaptic density protein 95; SD: Standard error; SDS-PAGE: Sodium dodecyl sulfate polyacrylamide gel electrophoresis; SEM: Standard error of the mean

\section{Acknowledgements}

We thank Prof. M.E. Greenberg (Harvard Medical School) for the luciferase reporter gene CRE-luciferase construct; Venus W.S. Lee and Yuki Y.K. Tang for their excellent technical assistance; Dr. Y.P. Ng and Dr. Ho-Kee Koon for critical comments on the manuscript.

\section{Funding}

This study was supported in part by the Hong Kong Research Grants Council Theme-based Research Scheme (T13-607/12R), the National Key Basic Research Program of China (2013CB530900), the Innovation and Technology Fund (GHP/ 037/05), the Innovation and Technology Fund for State Key Laboratory (ITCPD/ 17-9), the Shenzhen Peacock Plan, and the S.H. Ho Foundation.

\section{Availability of data and materials}

All data generated or analyzed during this study are included in this published article and its supplementary information file (Additional file 2).

\section{Authors' contributions}

$\mathrm{FCl}, \mathrm{YZ}, \mathrm{ZZ}$, and $\mathrm{NYI}$ conceived the project and designed the experiments. $\mathrm{FCl}$ and $\mathrm{KC}$ co-ordinate and supervise the project, as well as conducted final data analyses. YZ, EYC, OC and EPT conducted the experiments. GF prepared quality-controlled herbal extracts. FCl, KC and NYI prepared the manuscript. All authors read and approved the final manuscript.

\section{Competing interests}

The authors declare that they have no competing interests.

\section{Consent for publication}

Not applicable.

\section{Ethics approval and consent to participate}

The experimental procedures were approved by the Animal Ethics Committee of the Hong Kong University of Science and Technology (permission number 2008022).

\section{Author details}

'Division of Life Science, The Hong Kong University of Science and Technology, Clear Water Bay, Hong Kong, China. ${ }^{2}$ State Key Laboratory of Molecular Neuroscience, The Hong Kong University of Science and Technology, Clear Water Bay, Hong Kong, China. ${ }^{3}$ Guangdong Key Laboratory of Brain Science, Disease and Drug Development, HKUST Shenzhen Research Institute, Shenzhen, Guangdong, China. ${ }^{4}$ School of Chinese Medicine, Hong Kong Baptist University, Hong Kong, China. ${ }^{5}$ Present Address: Department of Pharmacology, School of Basic Medical Sciences, Capital Medical University, Beijing 100069, China.

Received: 6 February 2016 Accepted: 22 October 2016

Published online: 04 November 2016

\section{References}

1. Warlow C, Sudlow C, Dennis M, Wardlaw J, Sandercock P. Stroke Lancet. 2003;362(9391):1211-24

2. Donnan GA, Fisher M, Macleod M, Davis SM. Stroke Lancet. 2008;371(9624): 1612-23.

3. Pandya RS, Mao L, Zhou H, Zhou S, Zeng J, Popp AJ, Wang X. Central nervous system agents for ischemic stroke: neuroprotection mechanisms. Cent Nerv Syst Agents Med Chem. 2011;11(2):81-97.

4. Del Zoppo GJ, Saver JL, Jauch EC, Adams HP, Council AHAS. Expansion of the time window for treatment of acute ischemic stroke with intravenous tissue plasminogen activator: a science advisory from the American heart association/American stroke association. Stroke. 2009;40(8):2945-8.

5. Ginsberg MD. Neuroprotection for ischemic stroke: past, present and future. Neuropharmacology. 2008;55(3):363-89.

6. Cook DJ, Teves L, Tymianski M. Treatment of stroke with a PSD-95 inhibitor in the gyrencephalic primate brain. Nature. 2012;483(7388):213-7.

7. Lai TW, Zhang S, Wang YT. Excitotoxicity and stroke: identifying novel targets for neuroprotection. Prog Neurobiol. 2014;115:157-88.

8. Grupke S, Hall J, Dobbs M, Bix GJ, Fraser JF. Understanding history, and not repeating it. Neuroprotection for acute ischemic stroke: from review to preview. Clin Neurol Neurosurg. 2015;129:1-9.

9. Lipton SA, Rosenberg PA. Excitatory amino acids as a final common pathway for neurologic disorders. N Engl J Med. 1994;330(9):613-22.

10. Hazell AS. Excitotoxic mechanisms in stroke: an update of concepts and treatment strategies. Neurochem Int. 2007;50(7-8):941-53.

11. Lipton SA. Paradigm shift in neuroprotection by NMDA receptor blockade: memantine and beyond. Nat Rev Drug Discov. 2006;5(2):160-70.

12. Papadia S, Stevenson P, Hardingham NR, Bading H, Hardingham GE. Nuclear $\mathrm{Ca} 2+$ and the CAMP response element-binding protein family mediate a late phase of activity-dependent neuroprotection. J Neurosci. 2005;25(17):4279-87.

13. Aarts M, Liu Y, Liu L, Besshoh S, Arundine M, Gurd JW, Wang YT, Salter MW, Tymianski M. Treatment of ischemic brain damage by perturbing NMDA receptor- PSD-95 protein interactions. Science. 2002;298(5594):846-50.

14. Tymianski M. Novel approaches to neuroprotection trials in acute ischemic stroke. Stroke. 2013;44(10):2942-50.

15. Gong X, Sucher NJ. Stroke therapy in traditional Chinese medicine (TCM): prospects for drug discovery and development. Trends Pharmacol Sci. 1999; 20(5):191-6.

16. Sun X, Chan LN, Gong X, Sucher NJ. N-methyl-D-aspartate receptor antagonist activity in traditional Chinese stroke medicines. Neurosignals. 2003;12(1):31-8.

17. Cao J, Chen Z, Zhu Y, Li Y, Guo C, Gao K, Chen L, Shi X, Zhang X, Yang Z, et al. Huangqi-Honghua combination and its main components ameliorate cerebral infarction with Qi deficiency and blood stasis syndrome by antioxidant action in rats. J Ethnopharmacol. 2014;155(2):1053-60.

18. Huang ZS. The Chinese material medica, vol. 303. China: People's Medical Publishing House; 2002. p. 75-6.

19. Ember CR, Ember M. Encyclopedia of medical anthropology: health and illness in the world's cultures topics, vol. 1. New York: Kluwer Academic/ Plenum Publishers; 2004. p. 712.

20. Liao Y. Traditional Chinese medicine. England: Cambridge University Press; 2011. p. 65.

21. Jia W, Gao WY, Yan YQ, Wang J, Xu ZH, Zheng WJ, Xiao PG. The rediscovery of ancient Chinese herbal formulas. Phytother Res. 2004;18(8):681-6. 
22. Zhao LD, Wang JH, Jin GR, Zhao Y, Zhang HJ. Neuroprotective effect of buyang huanwu decoction against focal cerebral ischemia/reperfusion injury in rats-time window and mechanism. J Ethnopharmacol. 2012; 140(2):339-44.

23. Hou YC, Lu CK, Wang YH, Chern CM, Liou KT, Wang HW, Shen YC. Unique mechanisms of sheng yu decoction (shèng yù tang) on ischemic stroke mice revealed by an integrated neurofunctional and transcriptome analysis. J Tradit Complement Med. 2013;3(4):240-9.

24. Fu DL, Lu L, Zhu W, Li JH, Li HQ, Liu AJ, Xie C, Zheng GQ. Xiaoxuming decoction for acute ischemic stroke: a systematic review and meta-analysis. J Ethnopharmacol. 2013;148(1):1-13.

25. Li H, Xu W, Zhang YQ, Chu KD, Chen LD, Chen XW. Research on volatile components of gualou guizhi decoction and its components in rat brain by GC-MS. Zhongguo Zhong Yao Za Zhi. 2014;39(8):1509-15.

26. Xu JH, Huang YM, Ling W, Li Y, Wang M, Chen XY, Sui Y, Zhao HL. Wen Dan Decoction for hemorrhagic stroke and ischemic stroke. Complement Ther Med. 2015;23(2):298-308

27. Cheng FC, Chen WL, Wei JW, Huang KS, Yarbrough GG. The neuroprotective effects of BNG-1: a new formulation of traditional Chinese medicines for stroke. Am J Chin Med. 2005;33(1):61-71.

28. Gao Y, Zhong H, Ma B, Huang Y. Randomized, double-blind, parallel-controlled clinical trial on correspondence of prescriptions and traditional Chinese medicine syndrome of ischemic stroke. J Tradit Chin Med. 2012;32(3):335-42.

29. Flaws B, Kuchinski L, Casanas R. The treatment of diabetes mellitus with Chinese medicine. Boulder: Blue Poppy Press; 2002. p. 271.

30. Xiang J, Tang YP, Wu P, Gao JP, Cai DF. Chinese medicine Nao-Shuan-Tong attenuates cerebral ischemic injury by inhibiting apoptosis in a rat model of stroke. J Ethnopharmacol. 2010;131(1):174-81.

31. Fang WK, Weng YJ, Chang MH, Lin CC, Chen YS, Hsu HH, Tsai FJ, Tsai CH, Kuo WH, Lu CY, et al. Proliferative effects of chishao on injured peripheral neurons. Am J Chin Med. 2010;38(4):735-43.

32. Huang KS, Lu MJ, Chen YS, Tsai FJ, Kuo WW, Cheng YC, Lin CC, Tsai CH, Huang CY, Lin JG, et al. Proliferative effects of Chishao on Schwann cells are FGF-uPA, and ERK- and JNK-dependent. Am J Chin Med. 2009;37(6):1191-202.

33. Ju MS, Kim HG, Choi JG, Ryu JH, Hur J, Kim YJ, Oh MS. Cassiae semen, a seed of Cassia obtusifolia, has neuroprotective effects in Parkinson's disease models. Food Chem Toxicol. 2010;48(8-9):2037-44.

34. Drever BD, Anderson WG, Riedel G, Kim DH, Ryu JH, Choi DY, Platt B. The seed extract of Cassia obtusifolia offers neuroprotection to mouse hippocampal cultures. J Pharmacol Sci. 2008;107(4):380-92.

35. Lee HK, Yang EJ, Kim JY, Song KS, Seong YH. Inhibitory effects of glycyrrhizae radix and its active component, isoliquiritigenin, on abeta (25-35)-induced neurotoxicity in cultured rat cortical neurons. Arch Pharm Res. 2012:35(5):897-904

36. Cheng CY, Ho TY, Lee EJ, Su SY, Tang NY, Hsieh CL. Ferulic acid reduces cerebral infarct through its antioxidative and anti-inflammatory effects following transient focal cerebral ischemia in rats. Am J Chin Med. 2008; 36(6):1105-19.

37. Yu Y, Du JR, Wang CY, Qian ZM. Protection against hydrogen peroxideinduced injury by Z-ligustilide in PC12 cells. Exp Brain Res. 2008;184(3):307-12.

38. Peng HY, Du JR, Zhang GY, Kuang X, Liu YX, Qian ZM, Wang CY. Neuroprotective effect of Z-ligustilide against permanent focal ischemic damage in rats. Biol Pharm Bull. 2007;30(2):309-12.

39. Zhong J, Pollastro F, Prenen J, Zhu Z, Appendino G, Nilius B. Ligustilide: a novel TRPA1 modulator. Pflugers Arch. 2011;462(6):841-9.

40. Guo C, Tong L, Xi M, Yang H, Dong H, Wen A. Neuroprotective effect of calycosin on cerebral ischemia and reperfusion injury in rats. J Ethnopharmacol. 2012;144(3):768-74.

41. Lam BY, Lo AC, Sun X, Luo HW, Chung SK, Sucher NJ. Neuroprotective effects of tanshinones in transient focal cerebral ischemia in mice. Phytomedicine. 2003;10(4):286-91.

42. Li HQ, Wei JJ, Xia W, Li JH, Liu AJ, Yin SB, Wang C, Song L, Wang Y, Zheng $\mathrm{GQ}$, et al. Promoting blood circulation for removing blood stasis therapy for acute intracerebral hemorrhage: a systematic review and meta-analysis. Acta Pharmacol Sin. 2015;36(6):659-75.

43. Commission C. P. Pharmacopoeia of People's Republic of China (part one), vol. 1. Beijing: China Medicine Science and Technology Press; 2010.

44. Xie W, Zhao Y, Du L. Emerging approaches of traditional Chinese medicine formulas for the treatment of hyperlipidemia. J Ethnopharmacol. 2012 140(2):345-67.
45. Lewis A, Segal A. Hyperlipidemia and primary prevention of stroke: does risk factor identification and reduction really work? Curr Atheroscler Rep. 2010; 12(4):225-9.

46. Paoletti $\mathrm{P}$, Bellone $\mathrm{C}$, Zhou Q. NMDA receptor subunit diversity: impact on receptor properties, synaptic plasticity and disease. Nat Rev Neurosci. 2013; 14(6):383-400

47. Zhao Y, Li W, Chow PC, Lau DT, Lee NT, Pang Y, Zhang X, Wang X, Han Y. Bis (7)-tacrine, a promising anti-Alzheimer's dimer, affords dose- and timedependent neuroprotection against transient focal cerebral ischemia. Neurosci Lett. 2008;439(2):160-4.

48. Zhao Y, Dou J, Luo J, Li W, Chan HH, Cui W, Zhang H, Han R, Carlier PR, Zhang $X$, et al. Neuroprotection against excitotoxic and ischemic insults by bis (12)-hupyridone, a novel anti-acetylcholinesterase dimer, possibly via acting on multiple targets. Brain Res. 2011;1421:100-9.

49. Lo AC, Cheung AK, Hung VK, Yeung CM, He QY, Chiu JF, Chung SS, Chung SK. Deletion of aldose reductase leads to protection against cerebral ischemic injury. J Cereb Blood Flow Metab. 2007:27(8):1496-509.

50. Bederson JB, Pitts LH, Tsuji M, Nishimura MC, Davis RL, Bartkowski H. Rat middle cerebral artery occlusion: evaluation of the model and development of a neurologic examination. Stroke. 1986;17(3):472-6.

51. Ip FC, Fu WY, Cheng EY, Tong EP, Lok KC, Liang Y, Ye WC, Ip NY. Anemoside A3 enhances cognition through the regulation of synaptic function and neuroprotection. Neuropsychopharmacology. 2015;40:1877-87.

52. Wan J, Fu AK, Ip FC, Ng HK, Hugon J, Page G, Wang JH, Lai KO, Wu Z, Ip NY. Tyk2/STAT3 signaling mediates beta-amyloid-induced neuronal cell death: implications in Alzheimer's disease. J Neurosci. 2010;30(20):6873-81.

53. Chen HS, Lipton SA. Mechanism of memantine block of NMDA-activated channels in rat retinal ganglion cells: uncompetitive antagonism. J Physiol. 1997:499(Pt 1):27-46.

54. Fu G, Ip FC, Pang H, Ip NY. New secoiridoid glucosides from Ligustrum lucidum induce ERK and CREB phosphorylation in cultured cortical neurons. Planta Med. 2010;76(10):998-1003.

55. Takasu MA, Dalva MB, Zigmond RE, Greenberg ME. Modulation of NMDA receptor-dependent calcium influx and gene expression through EphB receptors. Science. 2002;295(5554):491-5.

56. Abele AE, Scholz KP, Scholz WK, Miller RJ. Excitotoxicity induced by enhanced excitatory neurotransmission in cultured hippocampal pyramidal neurons. Neuron. 1990:4(3):413-9.

57. Almeida RD, Manadas BJ, Melo CV, Gomes JR, Mendes CS, Grãos MM, Carvalho RF, Carvalho AP, Duarte CB. Neuroprotection by BDNF against glutamate-induced apoptotic cell death is mediated by ERK and PI3-kinase pathways. Cell Death Differ. 2005;12(10):1329-43.

58. Han BH, Holtzman DM. BDNF protects the neonatal brain from hypoxicischemic injury in vivo via the ERK pathway. J Neurosci. 2000;20(15):5775-81.

59. Sugiura S, Kitagawa K, Omura-Matsuoka E, Sasaki T, Tanaka S, Yagita Y, Matsushita K, Storm DR, Hori M. CRE-mediated gene transcription in the peri-infarct area after focal cerebral ischemia in mice. J Neurosci Res. 2004, 75(3):401-7.

60. Lonze BE, Ginty DD. Function and regulation of CREB family transcription factors in the nervous system. Neuron. 2002;35(4):605-23.

61. Rothwell PM, Giles MF, Chandratheva A, Marquardt L, Geraghty O, Redgrave $J N$, Lovelock CE, Binney LE, Bull LM, Cuthbertson FC, et al. Effect of urgent treatment of transient ischaemic attack and minor stroke on early recurrent stroke (EXPRESS study): a prospective population-based sequential comparison. Lancet. 2007:370(9596):1432-42.

62. Minnerup J, Sutherland BA, Buchan AM, Kleinschnitz C. Neuroprotection for stroke: current status and future perspectives. Int J Mol Sci. 2012;13(9):11753-72.

63. Chavez JC, Hurko O, Barone FC, Feuerstein GZ. Pharmacologic interventions for stroke: looking beyond the thrombolysis time window into the penumbra with biomarkers, not a stopwatch. Stroke. 2009;40(10):e558-63.

64. Wang JM, Chao JR, Chen W, Kuo ML, Yen JJ, Yang-Yen HF. The antiapoptotic gene mcl-1 is up-regulated by the phosphatidylinositol 3kinase/Akt signaling pathway through a transcription factor complex containing CREB. Mol Cell Biol. 1999;19(9):6195-206.

65. Riccio A, Ahn S, Davenport CM, Blendy JA, Ginty DD. Mediation by a CREB family transcription factor of NGF-dependent survival of sympathetic neurons. Science. 1999;286(5448):2358-61.

66. Kitagawa K, Matsumoto M, Tsujimoto Y, Ohtsuki T, Kuwabara K, Matsushita K, Yang G, Tanabe H, Martinou JC, Hori M, et al. Amelioration of hippocampal neuronal damage after global ischemia by neuronal overexpression of BCL-2 in transgenic mice. Stroke. 1998;29(12):2616-21. 
67. Tao X, Finkbeiner S, Arnold DB, Shaywitz AJ, Greenberg ME. Ca2+ influx regulates BDNF transcription by a CREB family transcription factordependent mechanism. Neuron. 1998;20(4):709-26.

68. Zhang Z, Zhao R, Qi J, Wen S, Tang Y, Wang D. Inhibition of glycogen synthase kinase-3beta by Angelica sinensis extract decreases beta-amyloidinduced neurotoxicity and tau phosphorylation in cultured cortical neurons. J Neurosci Res. 2011;89(3):437-47.

69. Lin $Y L$, Lee $Y C$, Huang CL, Lai WL, Lin YR, Huang NK. Ligusticum chuanxiong prevents rat pheochromocytoma cells from serum deprivation-induced apoptosis through a protein kinase A-dependent pathway. J Ethnopharmacol. 2007;109(3):428-34.

70. Guo X, Chen ZH, Wang HL, Liu ZC, Wang XP, Zhou BH, Yang C, Zhang XP, Xiao L, Shu C, et al. WSKY, a traditional Chinese decoction, rescues cognitive impairment associated with NMDA receptor antagonism by enhancing BDNF/ERK/CREB signaling. Mol Med Rep. 2015;11(4):2927-34.

71. Lee YW, Kim DH, Jeon SJ, Park SJ, Kim JM, Jung JM, Lee HE, Bae SG, Oh HK, Son $\mathrm{KH}$, et al. Neuroprotective effects of salvianolic acid B on an Abeta25-35 peptide-induced mouse model of Alzheimer's disease. Eur J Pharmacol. 2013;704(1-3):70-7.

72. Yi JH, Park HJ, Lee S, Jung JW, Kim BC, Lee YC, Ryu JH, Kim DH. Cassia obtusifolia seed ameliorates amyloid beta-induced synaptic dysfunction through anti-inflammatory and Akt/GSK-3beta pathways. J Ethnopharmacol. 2016;178:50-7.

73. Kim SW, Jin Y, Shin JH, Kim ID, Lee HK, Park S, Han PL, Lee JK. Glycyrrhizic acid affords robust neuroprotection in the postischemic brain via antiinflammatory effect by inhibiting HMGB1 phosphorylation and secretion. Neurobiol Dis. 2012;46(1):147-56.

74. Oh HA, Choi HJ, Kim NJ, Kim DH. Anti-stress effect of astragaloside IV in immobilized mice. J Ethnopharmacol. 2014;153(3):928-32.

75. Song SS, Yuan PF, Li PP, Wu HX, Ni WJ, Lu JT, Wei W. Protective effects of total glucosides of paeony on $\mathrm{N}$-nitrosodiethylamine-induced hepatocellular carcinoma in rats via down-regulation of regulatory B cells. Immunol Invest. 2015;44(6):521-35.

76. Saw $C L$, Wu Q, Su ZY, Wang H, Yang Y, Xu X, Huang Y, Khor TO, Kong AN. Effects of natural phytochemicals in Angelica sinensis (Danggui) on Nrf2mediated gene expression of phase II drug metabolizing enzymes and antiinflammation. Biopharm Drug Dispos. 2013;34(6):303-11.

77. Li CM, Guo YQ, Dong XL, Li H, Wang B, Wu JH, Wong MS, Chan SW. Ethanolic extract of rhizome of Ligusticum chuanxiong Hort. (chuanxiong) enhances endothelium-dependent vascular reactivity in ovariectomized rats fed with high-fat diet. Food Funct. 2014;5(10):2475-85.

78. Chen XX, Lin WL, Yeung WF, Song TH, Lao LX, Zhang YB, Meng W. Quality and safety control of Tumor-Shrinking Decoction (TSD), a Chinese herbal preparation for the treatment of uterine fibroids. Biotechnol Appl Biochem. 2015. doi:10. 1002/bab.1460. [Epub ahead of print]

79. Xu Q, Bauer R, Hendry BM, Fan TP, Zhao Z, Duez P, Simmonds MS, Witt CM, Lu A, Robinson N, et al. The quest for modernisation of traditional Chinese medicine. BMC Complement Altern Med. 2013;13:132.

80. Nowak-Sliwinska P, Weiss A, Ding X, Dyson PJ, van den Bergh H, Griffioen AW, Ho CM. Optimization of drug combinations using feedback system control. Nat Protoc. 2016;11(2):302-15.

81. Liang K, Ye Y, Wang Y, Zhang J, Li C. Formononetin mediates neuroprotection against cerebral ischemia/reperfusion in rats via downregulation of the $\mathrm{Bax} / \mathrm{BCl}-2$ ratio and upregulation PI3K/Akt signaling pathway. J Neurol Sci. 2014;344(1-2):100-4.

82. Tu Q, Wang R, Ding B, Zhong W, Cao H. Protective and antioxidant effect of Danshen polysaccharides on cerebral ischemia/reperfusion injury in rats. Int J Biol Macromol. 2013;60:268-71.

83. Lin YL, Tsay HJ, Lai TH, Tzeng T, Shiao YJ. Lithospermic acid attenuates 1methyl-4-phenylpyridine-induced neurotoxicity by blocking neuronal apoptotic and neuroinflammatory pathways. J Biomed Sci. 2015;22:37.

84. Chen $\mathrm{YH}, \mathrm{Du} \mathrm{GH}$, Zhang JT. Salvianolic acid B protects brain against injuries caused by ischemia-reperfusion in rats. Acta Pharmacol Sin. 2000;21(5):463-6.

85. Park OK, Choi JH, Park JH, Kim IH, Yan BC, Ahn JH, Kwon SH, Lee JC, Kim YS, Kim M, et al. Comparison of neuroprotective effects of five major lipophilic diterpenoids from Danshen extract against experimentally induced transient cerebral ischemic damage. Fitoterapia. 2012;83(8):1666-74.

86. Liu DZ, Xie KQ, Ji XQ, Ye Y, Jiang CL, Zhu XZ. Neuroprotective effect of paeoniflorin on cerebral ischemic rat by activating adenosine $A 1$ receptor in a manner different from its classical agonists. Br J Pharmacol. 2005;146(4):604-11.
87. Zhang N, Zhang X, Liu X, Wang H, Xue J, Yu J, Kang N, Wang X. Chrysophanol inhibits NALP3 inflammasome activation and ameliorates cerebral ischemia/reperfusion in mice. Mediators Inflamm. 2014;2014: 370530.

88. Nam KN, Kim KP, Cho KH, Jung WS, Park JM, Cho SY, Park SK, Park TH, Kim YS, Lee EH. Prevention of inflammation-mediated neurotoxicity by butylidenephthalide and its role in microglial activation. Cell Biochem Funct. 2013;31(8):707-12

89. Zhao H, Yang D, Shi M, Liang J, Yang X, Jin S. Clinical efficacy and safety of traditional Chinese medicine combined with Western Medicine in patients with diabetic acute ischemic stroke. J Tradit Chin Med. 2014;34(2):145-9.

90. Chen ZA, Wang JL, Liu RT, Ren JP, Wen LQ, Chen XJ, Bian GX. Liquiritin potentiate neurite outgrowth induced by nerve growth factor in PC12 cells. Cytotechnology. 2009;60(1-3):125-32.

91. Sun YX, Tang Y, Wu AL, Liu T, Dai XL, Zheng QS, Wang ZB. Neuroprotective effect of liquiritin against focal cerebral ischemia/reperfusion in mice via its antioxidant and antiapoptosis properties. J Asian Nat Prod Res. 2010; 12(12):1051-60.

\section{Submit your next manuscript to BioMed Central and we will help you at every step:}

- We accept pre-submission inquiries

- Our selector tool helps you to find the most relevant journal

- We provide round the clock customer support

- Convenient online submission

- Thorough peer review

- Inclusion in PubMed and all major indexing services

- Maximum visibility for your research

Submit your manuscript at www.biomedcentral.com/submit
C Biomed Central 